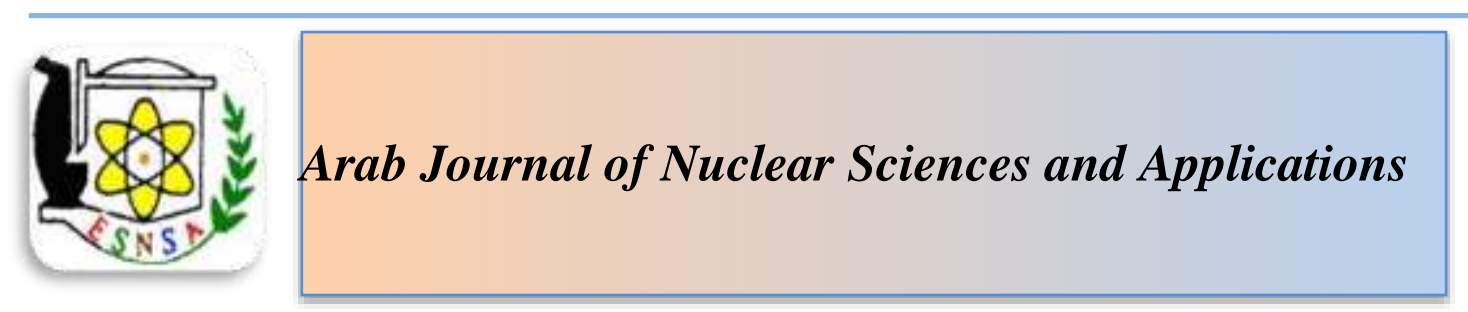

ISSN 1110-0451

Web site: ajnsa.journals.ekb.eg

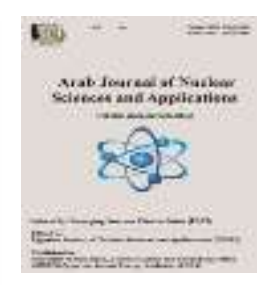

(ESNSA)

\title{
Radiation Synthesis of Gas Sensor Based on Polyaniline Nanoflake-Poly vinyl alcohol) Film for Four Hazardous Gases $\left(\mathrm{NH}_{3}, \mathrm{CO}_{2}, \mathrm{H}_{2} \mathrm{~S}\right.$ and phenol)
}

\author{
Ehab E. Khozemey, Mohamed M. Ghobashy, Tarek M. Mohamed \\ Radiation Research of Polymer chemistry department, National Center for Radiation Research and Technology, \\ Atomic Energy Authority, Cairo, Egypt
}

Received $24^{\text {th }}$ Nov. 2019 In this study, a low-cost conductive composite membrane consisting of polyaniline nano-flake, dispersed Accepted $23^{\text {th }}$ Apr. 2020 in a polyvinyl alcohol, has been prepared using in-situ polymerization technique. The polymerization of polyaniline was carried out based on polyvinyl alcohol using ammonium per sulfate as an oxidizing agent at low temperatures $\left(-5^{\circ} \mathrm{C}\right)$ in acid medium at $\mathrm{pH} 3 \mathrm{1M}(\mathrm{HCl})$ followed by exposure to gamma irradiation leading to crosslinging of (PANI-PVA) membranes and for enhancement formation of polyaniline nano-flake. The produced film is in the emeraldine oxidation state and fully protonated, which can detect the hazardous gases $\left(\mathrm{NH}_{3}, \mathrm{H}_{2} \mathrm{~S}, \mathrm{CO}_{2}\right.$ and phenol gas) through the change in the color and in the electrical conductivity. The gas-sensing property of (PANI-PVA) film was examined at ambient conditions of temperature and pressure. It was observed that the variation in sensing property of (PANI-PVA) films corresponding to the type of gases in the order $\mathrm{NH}_{3} \geq \mathrm{H}_{2} \mathrm{~S} \geq \mathrm{CO}_{2} \geq$ phenol gas. The product films of (PANI-PVA) after and before four gases adsorption were characterized by scanning electron microscopy, infrared spectroscopy, UV-Vis spectroscopy and XRD. TEM images of (PANI) obtained in form 2D-polyaniline nano-flake is confirmed. Furthermore, the incorporation of gas molecules into the PVA-PANI films for four gases adsorption and their conductivity changing was examined. It was observed that the conductivity changed according to the chemical structure changing of PANI as confirmed by FTIR data. It was found that, the electrical conductivity of all blended films decreases by exposure to the gas.

\section{Introduction}

Keywords: 2D-polyaniline nanoflake, gas sensor, ammonia, phenol, gamma irradiation.

Conducting polymers and their derivatives such as polythiophene, polypyrrole and polyaniline have been widely investigated as a gas sensor for toxic and hazardous gases since 1980s [1-3]. The advantages of conducting polymers as chemical sensors has achieved as high sensitive towards toxic gases such as $\mathrm{NH} 3$ and $\mathrm{H} 2 \mathrm{~S}$, room temperature operation, easy of detection and the possibility of using its physical or chemical properties in different applications [1, $\underline{4}, \underline{5}]$ Different preparation techniques are used such as chemical oxidative polymerization or electrochemical oxitative polymerization method. The impregnated of polyaniline (active polymer) through polyvinyl alcohol to manufacturing of applicable sensing film (crosslinked and elastic film) is urgent and good idea. Polyvinyl alcohol is suitable as a host matrix due to of its high mechanical strength, easy of processability and its dielectric properties. So, the obtained film has exhibit good optical and electrical properties $[2, \underline{3}, \underline{6-8}]$. Poly vinyl alcohol forms an excellent crooslinked flexible film induced by gamma irradiation. The successive of gamma irradiation technique in our preparation approach is that the aniline monomers are polymerized "in situ' a viscose solution of PVA by means of a two-step process: (i) Oxidative chemical polymerization of aniline monomer (ii) exposure the mixed solution to various gamma-irradiation doses (iii) casting the

Corresponding author: tarekmmm75@yahoo.com

DOI: $10.21608 / a j n s a .2020 .20000 .130$

(C) Scientific Information, Documentation and Publishing Office (SIDPO)-EAEA 
obtained green solution for forming of (PANIPVA) film (iv) chose a critical dose that induced crosslinking in high conversation. In this way, a fully protonated form of oxidative emaraldine (PANI-PVA) conductive film is obtained, containing 2D-polyaniline nanoflake in good dispersion form $[\underline{9}, \underline{10}]$.

Polyaniline unlike other conducting polymers, is can be exits in doped/undoped form depended on the $\mathrm{pH}$ of the media. Polyaniline is built up from repeat quinoid and benzenoid units of imine to amine groups, respectively [11-13]. The mechanism of conduction in these polymers is that, polymers exhibit electrical conductivity leading to formation of non-linear defects, formed during doping and deoping process leading to change in electrical charge and/ or color. The change in the conductivity or in color can be induced by the charge or protons transfer with the gas molecules by physical or chemical adsorption of the contact gas leading to the change in the formula of the active polyaniline such as leucoemeraldine (reduced form), emeraldine base (half oxidized form) and pernigraniline (partially fully oxidized form) to emeraldine salt (fully oxidized form) [1416].

This paper related with various aspects of the change physical chemistry structure of polyaniline by electrochemical and spectroscopic techniques and its suitability as a chemical sensor, particularly with four toxic gases $\left(\mathrm{NH}_{3}, \mathrm{H}_{2} \mathrm{~S}, \mathrm{CO}_{2}\right.$ and phenol). Gases interacting with polyaniline can be divided in two main classes: (i) chemical interact (ii) physical adsorption [17-19]. The chemical adsorption of gases on the polyaniline backbone is that alters the chemical structure and changes in its conductivity [20]. This is will underlie in this work. The effect of synthesis conditions such as doses of gamma irradiation was investigated.

\section{Experimental}

Radiation synthesis of $2 D$ nanoflake PAni Dispersions in PVA film.

Polyaniline (PANI) was synthesized by combining the conventional and novel methods by polymerization of polyaniline nanoflake based on polyvinyl alcohol using gamma irradiation. Dissolving $8 \mathrm{wt} \%$ of PVA in $100 \mathrm{ml}$ distilled water acid medium $1 \mathrm{M}(\mathrm{HCl})$ to prevent the precipitating of polyaniline (PANI) nanoparticles which formed during the polymerization process by chemical oxidative polymerization technique. The polymerization of ANI monomers is occurred by chemical oxidative polymerization using ammonium persulfate as an oxidizing agent, that have carefully designed according to the literatures to obtain polyaniline nanostructures based on polyvinyl alcohol (PVA) [ㅁ, 21-23]. The preparation is occurred by dissolving $8 \mathrm{gm}$ of PVA in an aqueous acidic solution of $100 \mathrm{ml} \mathrm{HCl}(\mathrm{pH} 3)$ at room temperature with continous stirring at 70 ${ }^{\circ} \mathrm{C}$ for $2 \mathrm{~h}$ until complete dissolving the PVA then leave to cool. $0.2 \mathrm{ml}$ of aniline monomers added to the PVA solution drop by drop in the presence of $0.02 \mathrm{gm}$ of Ammonium persulfate (APS). The reaction mixure was stirred for about $4 \mathrm{~h}$ at $-5{ }^{\circ} \mathrm{C}$ until the polyaniline formed in the the PVA solution converting the PVA solution to the dark green (emeraldine salt) (PVA/PANI) $\mathrm{HCl}$ film. The produced mixture will exposure to different irradiation doses $(0,2,4,6,8$ and $12 \mathrm{kGy})$ then poured into Petri dishes until dryness.

The irradiation process of (PVA/PANI) $\mathrm{HCl}$ films were performed in the ethylene bags under nitrogen at a dose rate of $1.22 \mathrm{kGy} / \mathrm{h}$. The obtained (PVA/PANI) is transparent green films.

The prepared crosslinked films were determined as follows:

The dried samples of the prepared films were soaked in distilled water for $24 \mathrm{~h}$ at $70{ }^{\circ} \mathrm{C}$. then left to dry to a constant weight. The gel content was calculated by applying the following formula:

Gel content $(\%)=\frac{\mathrm{W}_{\mathrm{d}}}{\mathrm{W}_{0}} \times 100$

Where $\mathrm{W}_{\mathrm{d}}$ and $\mathrm{W}_{0}$ are the weights of dried samples after and before soaking in distilled water, respectively.

\section{The swelling measurements}

The degree of water swelling of (PVA/PANI) $\mathrm{HCl}$ film was determined by weighting the dry sample and the sample conditioned in a glass vessel saturated with water. This procedure was repeated until the film reached a constant weight (equilibrium water uptake). The water swelling degree $(\%)$ of membrane was calculated according to the following equation:

Swelling (\%) $=\frac{\mathrm{w}_{\mathrm{s}}-\mathrm{w}_{\mathrm{d}}}{\mathrm{w}_{\mathrm{d}}} \times 100$

Where $\mathrm{W}_{\mathrm{d}}$ and $\mathrm{W}_{\mathrm{s}}$ are the weights of the dry and the swelled film, respectively. 


\section{characterizations}

FTIR spectra of (PVA/PANI) $\mathrm{HCl}$ before and after gas adsorption were scanned over the range of 400-4000 $\mathrm{cm}^{-1}$, on Bruker, Unicom infra-red spectrophotometer, Germany.

The morphology of (PVA-PANI) $\mathrm{HCl}$ surfaces after and before gas adsorption was examined using scanning electron microscopy model JEOLJSM- 5400, Tokyo, Japan. Before the examination, the samples were dried, coated with sputtered gold, observed and photographed.

X-ray diffraction (XRD) measured by using Shimadzu XRD 6000 diffractometer with $\mathrm{Cu}$ target. The XRD runs were carried out over the 20 ranging from $10^{\circ}$ to $40^{\circ}$ at a scan speed of $8 \%$ min.

The spectrophotometers for (PVA/PANI) $\mathrm{HCl}$ films were determined on an UV-Vis at room temperature and $37.5 \%$ relative humidity.

Thermogravimetric analysis of the prepared films was carried out using Shimadzu, Japan; TGA system of type TGA-50 at heating rate of (20 ${ }^{\circ} \mathrm{C} / \mathrm{min}$ ). The temperature ranged from ambient to $600{ }^{\circ} \mathrm{C}$. The experiments were performed under 20 $\mathrm{ml} / \mathrm{min}$ nitrogen flow.

\section{Result and Discussion}

Preparation of chemical sensor is very necessary and wide spread for detection of toxic and hazardous gases. However, production of thin films is limited due to the complexity of preparation crosslinked sensing film. Preparation of chemical oxidative emeraldine film of (PVA/PANI) is promising due to easy of processing and handling.

\section{Gel content and swelling}

The gelation percentage of (PVA/PANI) films as a function of irradiation dose was shown in Fig. 1. The gel content of the hydrogel increases with irradiation due to more radicals is formed by the effect of gamma irradiation. The radicals on the neighboring chains become close together, lead to improving the crosslinks and the gelation percentage.from the figure, it is observed that acceptable gelation was performed about $90 \%$ at irradiation dose $12 \mathrm{kGy}$. This means a high ability of flour to combine with AAc monomer at low doses. The increase in irradiation dose enhances the crosslinking and the gelation percentage about $90 \%$. This irradiation dose is suitable for the production of gas sensor films.

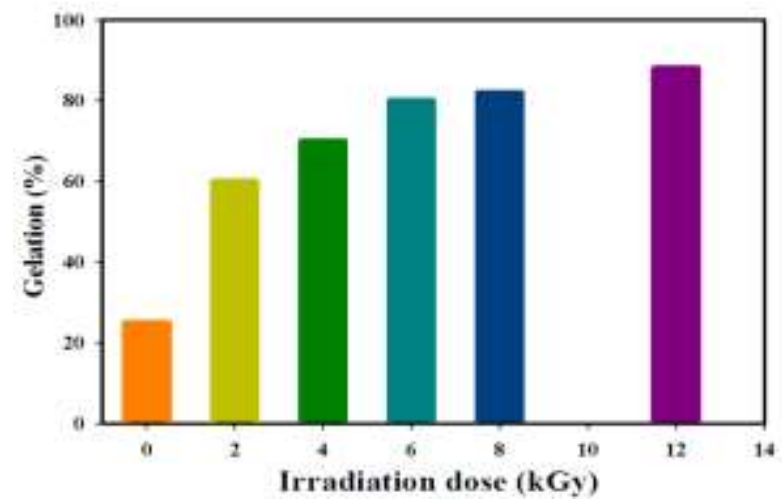

Figure (1): Effect of Irradiation dose on the gelation percentage for (F/AAc)

\section{Swelling behavior}

The effect of time on the swelling percentage of (PVA/PANI) films at different irradiation doses represented in figure 2. Shows the time dependent water uptake of the (PVA/PANI) films and the swelling increases with time until the equilibrium state is achieved after $6 \mathrm{~h}$. Thereafter, no significant change was observed. The data clearly shows that, the degree of swelling decreases with irradiation dose due to the increment in the crosslinking and hence a decrease in the swelling percentage is obtained.

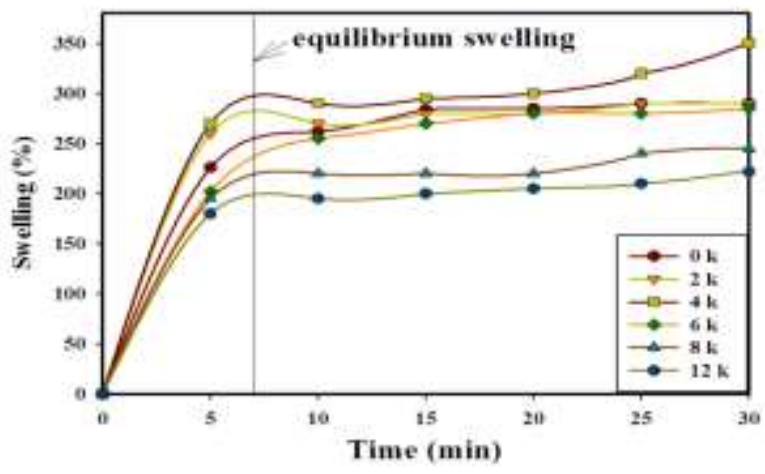

Figure (2): Effect of time on water uptake (\%) for the (PVA/PANI) at different irradiation dose

Physicochemical characterization and gas sensing property of the (PAni-PVA) identified by FTIR, $X R D$ and $U V$ spectroscopy.

The gas sensing property of the (PVA/PANI) was investigated by simple visual color change method. The sensor test was set up by purging the gas 
through the film of the (PVA/PANI) for 1 minute. On exposure to $\mathrm{NH}_{3}, \mathrm{H}_{2} \mathrm{~S}, \mathrm{CO}_{2}$ and Phenol gases the (PVA/PANI) changes color from green to blue, white, deep green, pale green, respectively as shown in Figure $\underline{3}$. All sensing measurements were carried out at room temperature.

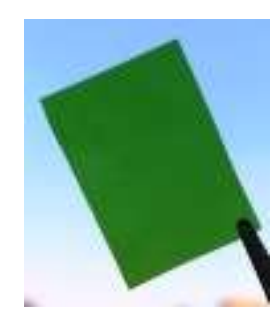

Blank film (a)

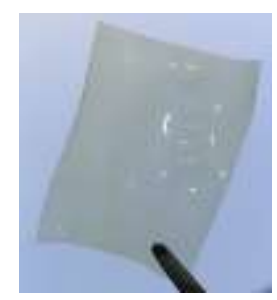

$\mathrm{H}_{2} \mathrm{~S}(\mathrm{c})$

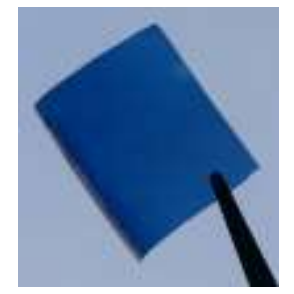

$\mathrm{NH}_{3}(b)$

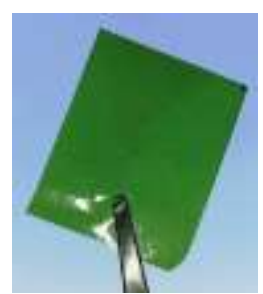

$\mathrm{CO}_{2}(\mathrm{~d})$

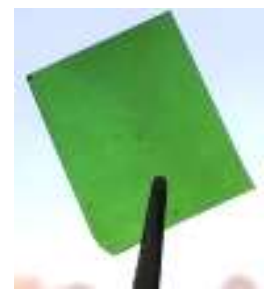

Phenol (e)

Figure (3): The color change response of the (PAni-PVA) sensor: (a) represents the original black color of the unexposed film (PVA/PANI) (b) represents the blue color of the film in presence of $\mathrm{NH}_{3}$ gas (c) $\mathrm{H}_{2} \mathrm{~S}(\mathrm{~d}) \mathrm{CO}_{2}$ (e) phenol

In order to investigate the effect of gas adsorbed by (PVA/PANI) film sensor among the chemical structure, physical properties and correlation to the electrical conductivity were performed. FTIR spectrum of (PVA/PANI) in Fig. 4a shows the characteristic of benzenoid ring stretching peak at $1421 \mathrm{~cm}^{-1}$ and absent of quinoid ring at $1570 \mathrm{~cm}^{-1}$ [9]. In addition, the absent of quinoid ring is observed also in the FT-IR spectrum corresponding to (PVA/PANI) after four gases adsorption in Figure $4 \mathrm{~b}$-e. That could attributed to the quinoid ring is cross-linked to give polyaniline 2D-nanoflake as shown in Figure 4f [24]. FTIR spectrum representative the formation of twodimensional polyaniline nanoflake explained by quinoid cross-linking mechanism in PVA matrices that stabilized by resonance forms of the aniline radical $[25,26]$. It is well contribute to the electrical conductivity of (PVA/PANI) early. The two strong stretching peaks at $1324 \mathrm{~cm}^{-1}$ and 1085 $\mathrm{cm}^{-1}$ are assigned to $\mathrm{C}-\mathrm{N}$ of tertiary aromatic amine and the stretching vibration attributed to inplane-bending of the - $\mathrm{CH}$ groups in the benzene ring, respectively [27]. The peak at $841 \mathrm{~cm}^{-1}$ is bending vibration due to para-di-substituted of (1, $4 \mathrm{C}-\mathrm{H}$ ) in benzene ring (present due polymerization of (ANI) $[\underline{28}, 29]$. The peak at 588 $\mathrm{cm}^{-1}$ is assigned to para coupling of the benzenoid ring. These results clearly suggest the successful summarization of aniline as 2D crosslinked flak shape as will draw eventually in Figure 4f. The broad peak located at $3259 \mathrm{~cm}^{-1}$ start from 3000 $\mathrm{cm}^{-1}$ to $3650 \mathrm{~cm}^{-1}$ is assigned to $\mathrm{N}-\mathrm{H}$ stretching of aromatic amine and $\mathrm{OH}$ groups in PVA matrix. In addition, PVA matrices shown the characteristic two peaks at $2916 \mathrm{~cm}^{-1}$ and $2851 \mathrm{~cm}^{-1}$ are correspond to symmetric and asymmetric $\mathrm{C}-\mathrm{H}$ stretching. The low intensity peak at $1736 \mathrm{~cm}^{-1}$ is attributed to the $\mathrm{C}=\mathrm{O}$ groups of PVA that residue from the hydrolysis of polyvinyl acetate in PVA production process [30]. The peak at $1143 \mathrm{~cm}^{-1}$ of PVA, assigned to C-O stretching [31] shifts by 5 $\mathrm{cm}^{-1}$ to $1138 \mathrm{~cm}^{-1}$ which are due to the formation of hydrogen bonding between hydroxyl groups of (PVA) and positively charged amine and imine sites of PANI matrices [32]. The peak located at $1653 \mathrm{~cm}^{-1}$ is can due to the bending vibration of primary amine $\left(\mathrm{NH}_{2}\right)$ groups. Figure $4 \mathrm{~b}$ of $\mathrm{NH}_{3}$ (PVA/PANI) show the peak at $1653 \mathrm{~cm}^{-1}$ more intensity than FTIR of pure (PVA/PANI) due to the $\mathrm{NH}_{3}$ capture $\mathrm{H}$ proton. Furthermore, FTIR indicated the adsorption of $\mathrm{H}_{2} \mathrm{~S}$ and the direct interaction with the amine group and convert it to ammonium ions [33]. Figure $4 \mathrm{c}$ show the peak at $1228 \mathrm{~cm}^{-1}$ and $609 \mathrm{~cm}^{-1}$ corresponding to $\mathrm{H}-\mathrm{S}$ in cases (PVA/PANI) $\mathrm{H}_{2} \mathrm{~S}$. Figure $4 \mathrm{~d}$ represent the corresponding peak of $\mathrm{CO}_{2}$ adsorbed on (PVA/PANI) at $1757 \mathrm{~cm}^{-1}$ at is corresponding to the chemical interaction of $\mathrm{CO}_{2}$ and polyaniline [34]The FTIR spectrum of $\mathrm{CO}_{2}$ (PVA/PANI) is similar to those of (PVA/PANI) $\mathrm{H}_{2} \mathrm{~S}$ which produced an alkyl-ammonium carbamate species and ammonium ion pair. In Figure $4 \mathrm{e}$ show the FTIR peak at $1597 \mathrm{~cm}^{-1}$ is attributed to benzene ring of phenol [35].

The adsorption of $\mathrm{NH}_{3}$ lead to increase in the FTIR intensity peak at $1648 \mathrm{~cm}^{-1}$ for the $\delta\left(\mathrm{NH}_{2}\right)$ 
deformation vibration compare to the blank sample at Figure 4a. Also, the $\mathrm{H}_{2} \mathrm{~S}, \mathrm{CO}_{2}$ and phenol adsorption are causes the shoulder and decreased the intensity peak at $1653 \mathrm{~cm}^{-1}$ for the $\delta\left(\mathrm{NH}_{2}\right)$ with little shift. These due to the intermolecular

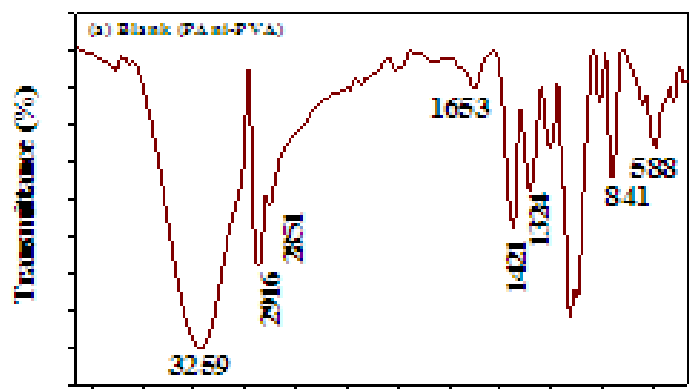

2000260022002000270024002100150015001200000600 Waven umber $\left(\mathrm{cm}^{-1}\right)$

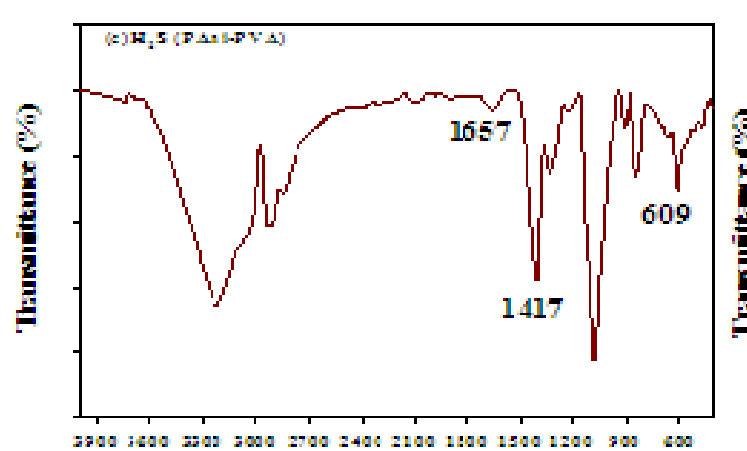
Wavernmber $\left(\mathrm{am}^{-1}\right)$

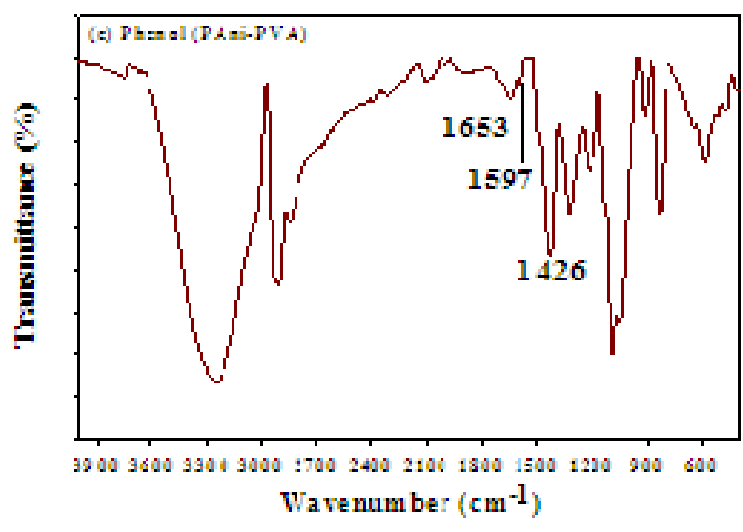

interaction between the three adsorptions gases are gave the ammonium ion e.g. $\left({ }^{+} \mathrm{N}-\mathrm{H}\right) \cdot{ }^{\cdot} \mathrm{SH}-$ and $(\mathrm{N}-\mathrm{H} \cdots \mathrm{O})$ and $(\mathrm{N}-\mathrm{H} \cdots \mathrm{O}=\mathrm{C}=\mathrm{O})$ in cased phenol and $\mathrm{CO}_{2}$ adsorption, respectively.
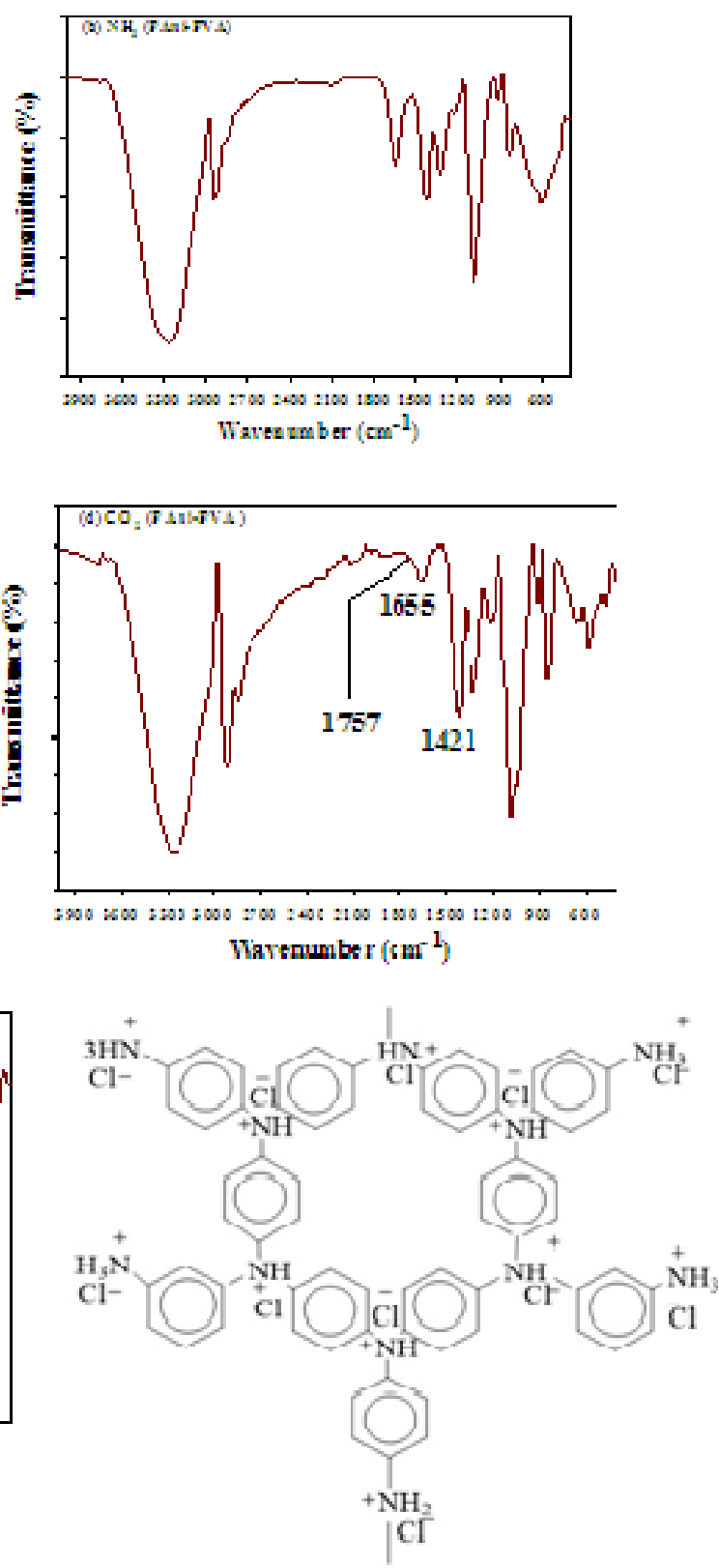

Fig. (4): The FTIR spectra of PVA/PAni (a) and PVA/PAni after four gases adsorption (b-e) films and (f) the cross-linking of polyaniline 
Fig. 5 shows the UV spectroscopy for prepared films of (PVA/PANI) sensor before and after adsorption of $\left(\mathrm{NH}_{3}, \mathrm{H}_{2} \mathrm{~S}, \mathrm{CO}_{2}\right.$ and phenol gases). The conjugated polymers are often highly colored because their $\pi-\pi$ energy gap falls within the visible region. Typically, the absorbance peak at $797 \mathrm{~nm}$ that owing to the formation of PANI with green color in case of emeraldine salt [36] that shift to blue color (emeraldine base) at absorbance peak of $635 \mathrm{~nm}$ due to adsorption of $\mathrm{NH}_{3}$ gas. The absorbance peak at $512 \mathrm{~nm}$ is results in the formation of the fully protonated polyaniline (PANI) $\mathrm{HCl}$ emeraldine hydrochloride [37] for $\pi$ polaron benzenoid to quinoid excitonic transitions. The absorption band around $398 \mathrm{~nm}$ is ascribed to the polaron $-\pi$ with similar bands were observed at $367 \mathrm{~nm} \mathrm{[38]}$ the red shift to high wave length due to propale interaction of PANI and PVA matrixes. The red-shift indicates the improved emerladine structure, consequently further improvement in the degree of doping and fully protonated structure of PANI [39]. The strong interaction of these polyanilines with PVA through hydrogen bonding between hydroxyl groups of PVA and positively charged amine and imine sites of PANI. The absorption peak at $980 \mathrm{~nm}$ of the $\pi$ - polaron transition of emeraldine salt of polyaniline
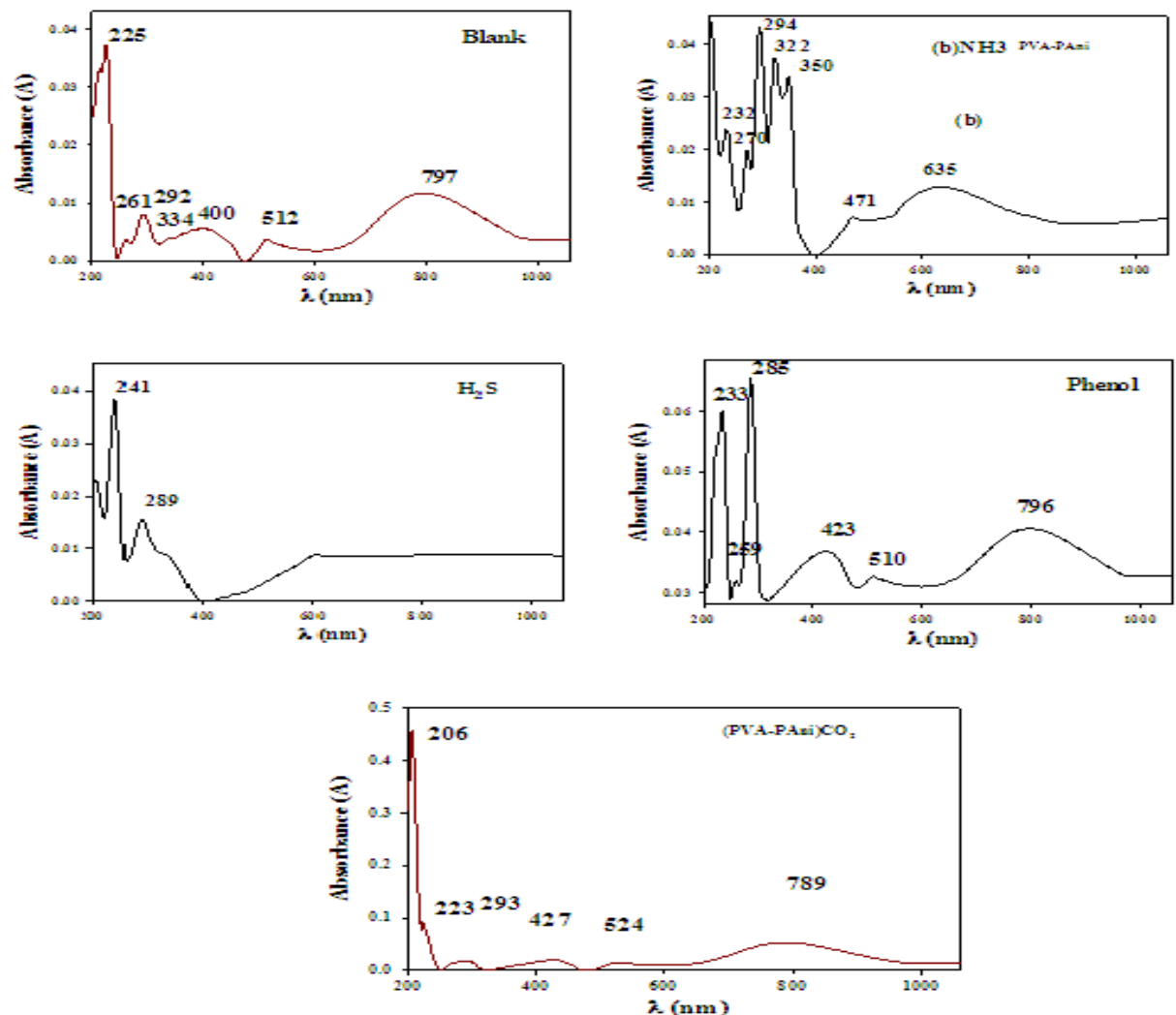

Fig. (5): UV-Vis-NIR absorption spectra obtained PAni nanoflake sensors on PVA film

Arab J. Nucl. Sci. \& Applic. Vol. 53, No. 3 (2020)

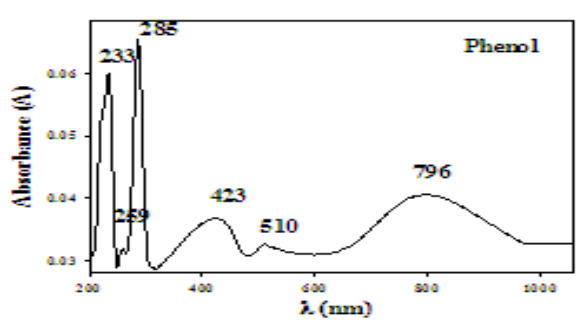

emeraldine salt is disappears [40]. This could due to formation of multi-hydrogen bonding with imine/amine groups of PANI matrices [41]. The brooding absorption peak at $400 \mathrm{~nm}$ due to the polaron-bipolaron band transition confirms the deposition of the emeraldine salt form of PANI and the broad is due to the hydrogen-bonding. In Figure $5 \mathrm{~b}$ for $\mathrm{NH}_{3}$ (PVA/PANI) has two absorption peaks at 322 and $635 \mathrm{~nm}$ has been suggested to arise from excitation of the benzene segment including amine and imines groups in PANI matrices, respectively. The UV-VIS spectra of both doped (PVA/PANI) $\mathrm{HCl}$ and undoped polyanilines $\mathrm{NH}_{3}$ (PVA/PANI) are shown in Fig. 5 a, b. The UV-vis absorption spectra of PANI (PVA/PANI) $\mathrm{HCl}$ is higher wavelength than $\mathrm{NH}_{3}$ (PVA/PANI) the possible reason may be the presence of lighter dopant ions $\left(\mathrm{Cl}^{-}\right)$in PANI

$(\mathrm{HCl})$ with higher charge mobility compared to $\mathrm{NH}_{3}$ (PVA/PANI). The (PVA/PANI) blank sample displays a strong absorption band located at 225 $\mathrm{nm}$ and low absorption band at, which are attributed to $\pi-\pi$ transitions of the aromatic $C=C$ bonds and $261 \mathrm{~nm}, 292 \mathrm{~nm}$ are attributed to the $\mathrm{n}-$ $\pi$ transitions of the $\mathrm{C}=\mathrm{O}$ groups along the polymer chains [42]. 
After $\mathrm{NH}_{3}$ adsorption the doped polyaniline becomes doped PANI and the absorption peaks at $225 \mathrm{~nm}, 261 \mathrm{~nm}$ and $292 \mathrm{~nm}$ at Fig. 5a were bathochromic shift red shifts to 232, 270 and 294 $\mathrm{nm}$ at Fig. 5b due to the un-doping structure of PANI lead to change the color of from green (PVA/PANI) $\mathrm{HCl}$ to blue (PVA/PANI) $\mathrm{NH}_{3}$. The shouldering of the absorption peaks of (PVA/PANI) blank after gases adsorption of $\mathrm{H}_{2} \mathrm{~S}$ $\mathrm{CO}_{2}$ and phenol is due to the change of fully protonated (doping) polyaniline structure that could lead to change in the colors of (PVA/PANI) colors as shown in Fig. 5 c-e curves.

The XRD patterns For (PVA/PANI) in Fig. 6 show a sharp diffraction peak at $2 \theta=19.7^{\circ}$ is reflecting to a high degree of crystallinity, which is due to the existence of inter- and intra-molecular hydrogen bond between PVA and PANI matrices $[\underline{30}, \underline{43}]$. The intensity of this peak decreased after (NH3, H2S and Phenol) gases adsorption But the intensity in case (PVA-PANI)- $\mathrm{CO}_{2}$ is increased about $30 \%$ due to (PVA/PANI)-CO2 membrane have high permeability that lead to the increased in order of PVA chains [44]. The XRD pattern for (PVA/PANI) in Fig. 6 exhibits three diffraction peaks located at $2 \theta=18.0^{\circ}$ [45] $23.5^{\circ}, 35,8^{\circ}, 39^{\circ}$ and $48.3^{\circ}$. These peaks indicate the highly protonated of (PVA/PANI) matrices [46]. This is an indication of While small intensity peak for (PVA/PANI)-Phenol indicated the rearrangement in the two polymers chain of PVA and PANI by hydrogen bond interactions at $2 \theta=6.5^{\circ}, 20.4^{\circ}$ for arises up out of the advancement of a lamella among the chains of polyaniline [47].

\section{Morphology of (PVA/PANI) films before and after adsorption}

Figure 7 (a-e) shows the scanning electron microscopy (SEM) of the (PVA/PANI) films as the sensor materials before and after absorption of four gases. These figures shows that Small scales are distributed in the surfaces of the films represented the flake structure of $2 \mathrm{D}$ polyaniline. The particles of polyaniline completely covered the surface of PVA which enhances the diffusion and adsorption of gase on the surfaces and the reaction between the gas molecules and polyaniline becomes more easily. From the figures it can be concluded that, the polyaniline nanoflake are interacting with polyvinyl alcohol. Figure $7 f$ show the transition electron microscopy (TEM) of the (PVA/PANI) membranes. Figure $7 f$ confirms the two dimentional flaky structure of the polyaniline nanostructure that forms due to the use of gamma rays during polymerization process (High dielectric response of 2D-polyaniline nanoflake based epoxy nanocomposites $\dagger$ Meher Wan, :a $^{*}$ Anoop K. Srivastava, $\$ b$ Punit K. Dhawan,c Raja Ram Yadav,c

Sudhindra B. Sant,a Ram Kripalc and Ji-Hoon Lee RSC Adv., 2015, 5, 48421-48425. DOI: $10.1039 / \mathrm{c} 5 \mathrm{ra} 05660 \mathrm{~h})$.

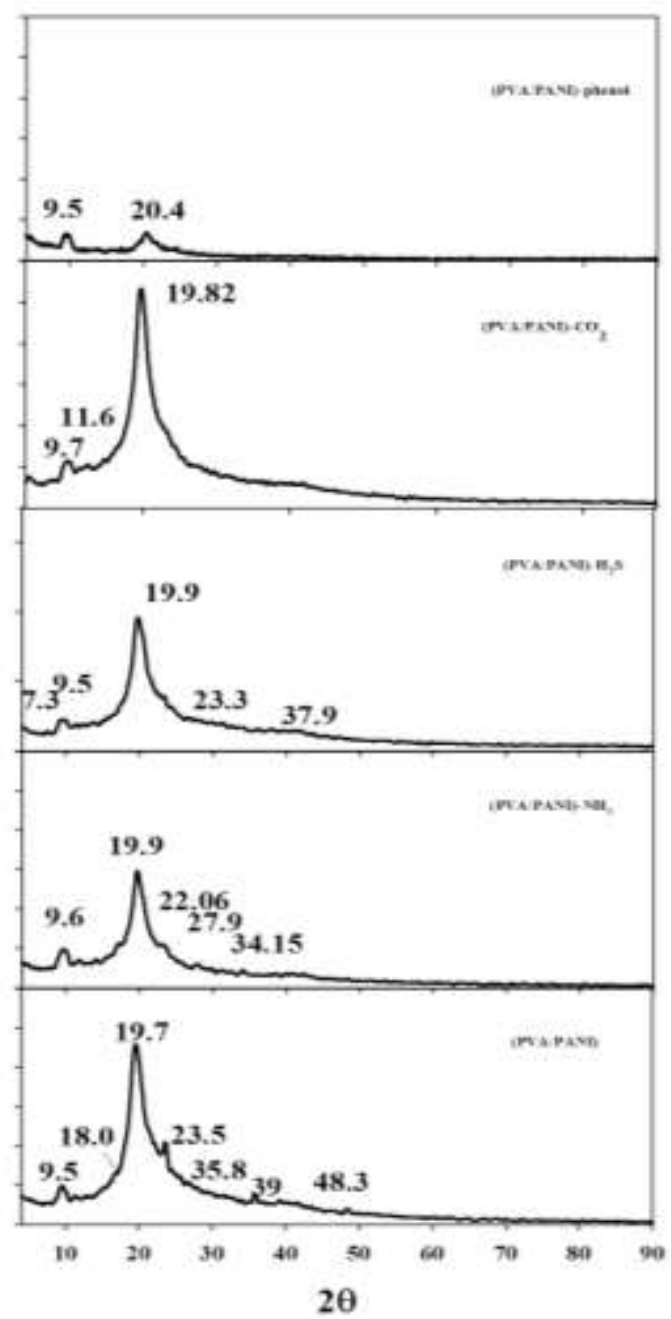

Fig. (6): The XRD patterns of (PVA/PANI) before and after gas adsorption 
Gas sensing measurements of (PAni-PVA) dependent on conductivity

As shown in Figure 11 the electrical conductivity of pure (PVA/PANI) film (emeraldine salt) decreases when the film is subjected to different four gases $\left(\mathrm{NH}_{3}, \mathrm{H}_{2} \mathrm{~S}, \mathrm{CO}_{2}\right.$ and phenol). It is obvious that, the degree of conductivity depend on the kind of adsorbed gas which leads to the reduction of electrical conductivity. The exposure of conductive (PAni-PVA) film to different gases like ammonia gas is governed by the protonation/deprotonation phenomena. In the electrically conductive state, PANI is a P-type semiconductor with $\mathrm{N}^{+}-\mathrm{H}$ adsorption sites. The
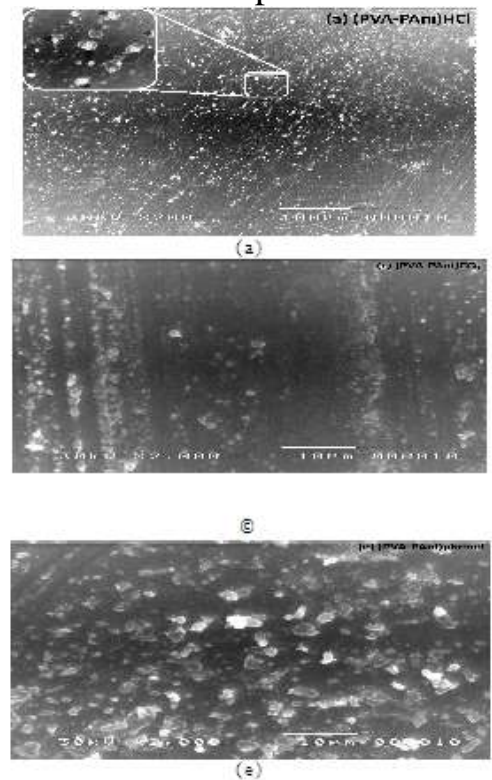

resistance change will be modulated by the protonation-deprotonation brought by ammonia gas [48]. As ammonia gas is penetrated PAni Network, they eliminate protons from emeraldine sites to form energetically more favorable $\mathrm{NH}_{4}{ }^{+}$. This deprotonation process reduces PANI from the emeraldine salt state to the emeraldine base state, leading to the reduced hole density in the PAni and thus reduced the conductivity. When the sensor is purged with dry air, the process is reversed, $\mathrm{NH}_{4}{ }^{+}$ decomposes to form $\mathrm{NH}_{3}$ and a proton, and the initial structure of PANI recovers.
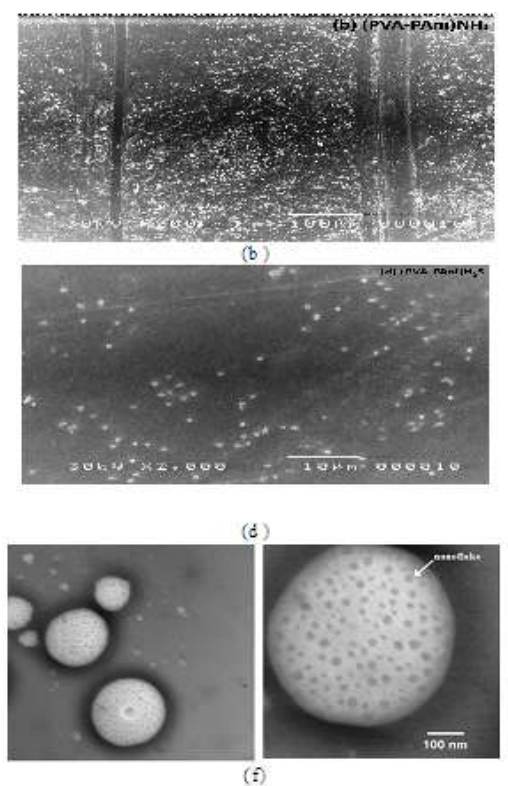

Fig. (7): SEM images of (PVA-PANI) before and after gas adsorption (a-e) and Transition electron Microscopy (f)
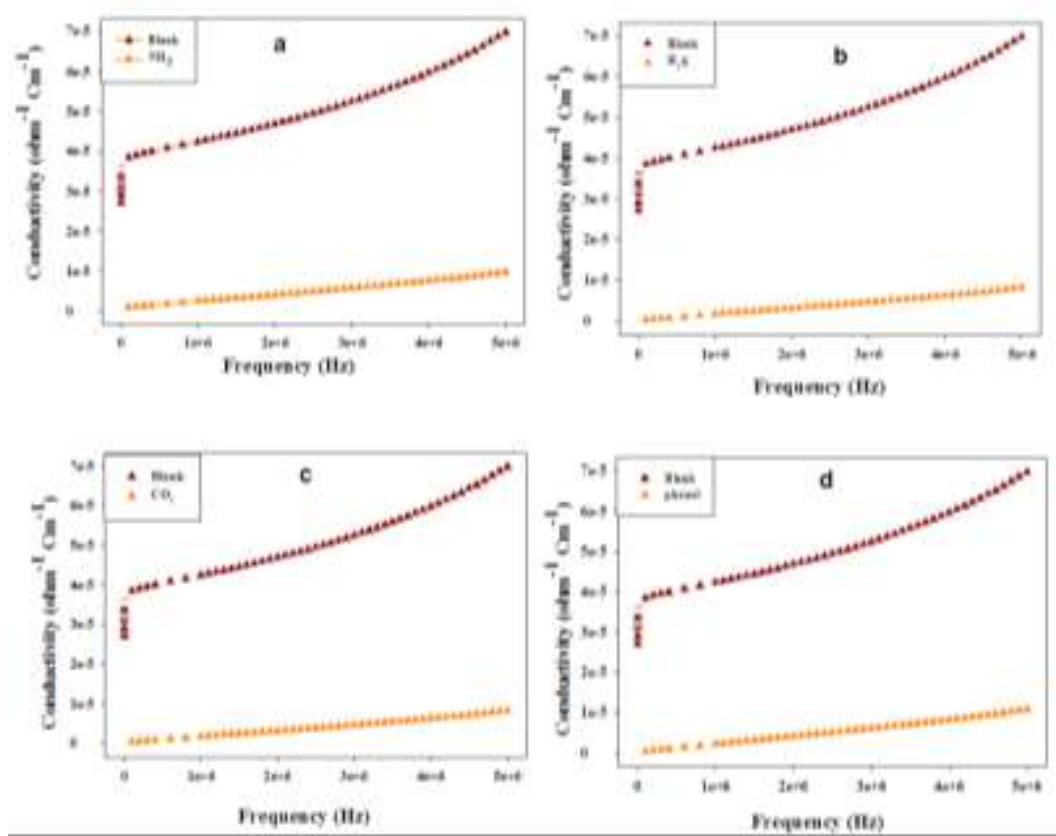

Fig. (8): Effect of the frequency on the conductivity of (PVA/PANI) membranes before and after gas adsorption 
The resistivity change for a conducting pure (PVA/PANI) film obtained in deionized water-HCl system upon exposure to four hazardous gases is given in Figure 9. Increase in resistance of pure (PVA/PANI) film upon exposure to four gases was observed. The increase in the resistance in the case of pure polymer when exposure to gases is in order $\mathrm{NH}_{3}$, phenol, $\mathrm{CO}_{2}$ and $\mathrm{H}_{2} \mathrm{~S}$. This drastic difference reveals the sensitivity of the (PVA/PANI) film to the hazardous gases.

\section{Conclusion}

Polyaniline was prepared by chemical oxidative polymerization in-situ polyvinyl alcohol solution followed by radiation polymerization to produce (PVA/PANI) gas sensor. The obtained 2D nanoflake PANi embedded into PVA film was characteristic by TEM. The spectroscopic studies referred that the change of physic chemical properties of (PVA/PANI) after gas adsorption is due to the intermolecular hydrogen bond formation between gas and aniline molecules. These confirm that the affinity of aniline toward gases adsorption. These results were further supported by conductivity measurements of (PVA/PANI) film as gas sensor. The conductivity of (PVA/PANI) was reduced depended on the kind of adsorbed gas lead to PAni in different oxidation state. Furthermore, the porosity of PVA matrices that is responsible on how gases can diffuse rapidly and then reacts with the sensitive PANI material for better sensor performance.

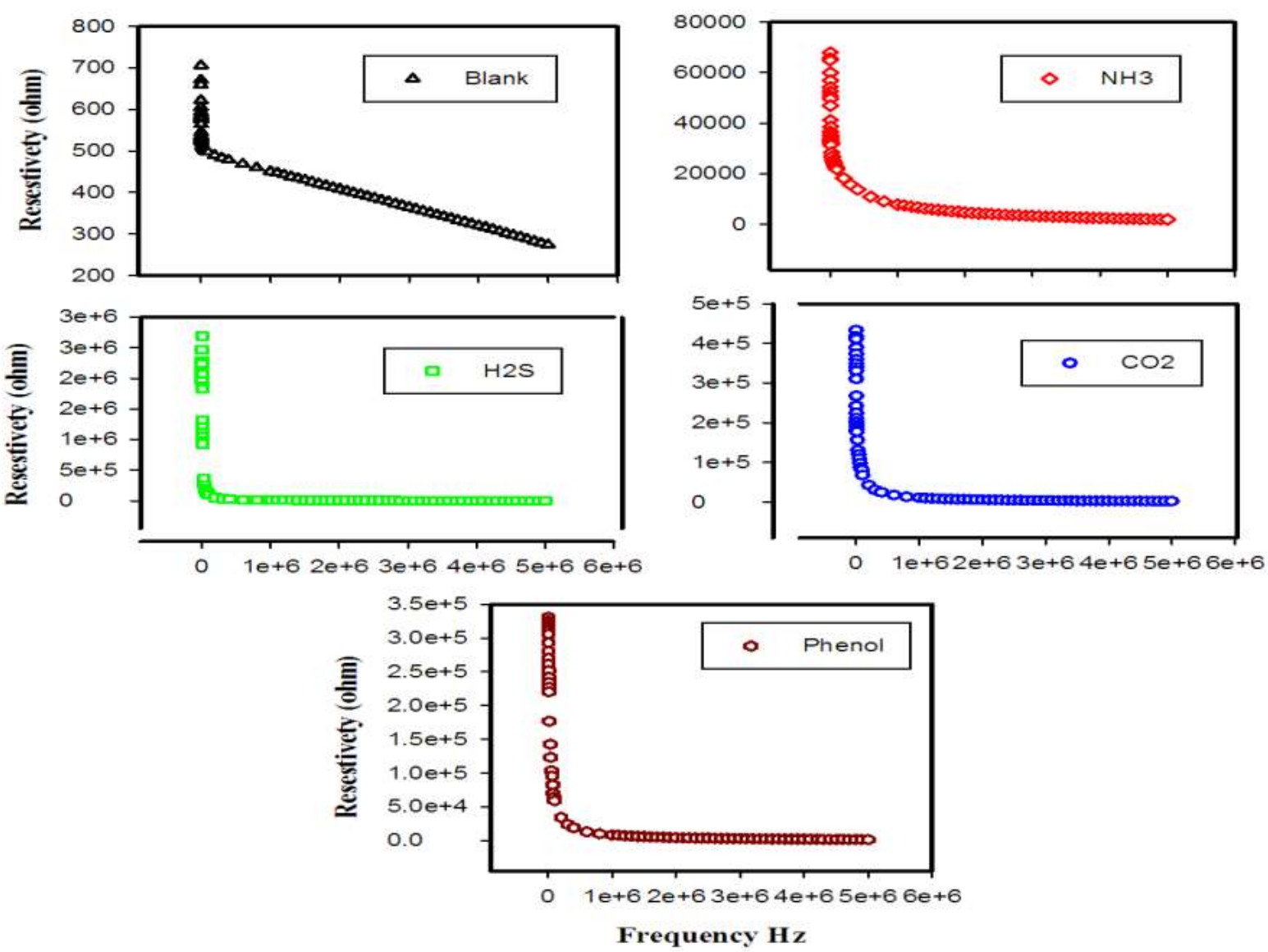

Fig. (9): Effect of the resistivity for (PVA/PANI) films before and after exposure to four hazardous gases 


\section{References}

1- Albuquerque, J., Mattoso, L., Balogh, D. T., Faria, R. M., Masters, J., \& MacDiarmid, A. (2000). A simple method to estimate the oxidation state of polyanilines. Synthetic Metals, 113(1-2), 19-22. https://doi.org/10.1016/S0379-6779(99)00299-4

2-Ali, M. A., Saion, E., Yahya, N., Kassim, A., Dahlan, K. M., \& Hashim, S. (2007). Synthesis of conducting polyaniline nanocomposites by radiation doping. Journal of Engineering Science and Technology, 2(1), 111-118.

3-Anju, V., Jithesh, P., \& Narayanankutty, S. K. (2019). A novel humidity and ammonia sensor based on nanofibers/polyaniline/polyvinyl alcohol. Sensors and Actuators A: Physical, 285, 35-44. https://doi.org/10.1016/j.sna.2018.10.037

4-Babu, V. J., Kumar, V. P., Subha, G., Kumari, V., Natarajan, T., Nair, A. S., . . Rahman, B. A. (2011). AC conductivity studies on PMMA-PANI ( $\mathrm{HCl})$ nanocomposite fibers produced by electrospinning. Journal of Engineered Fibers and Fabrics, 6(4). https://doi.org/10.1177/155892501100600408

5-Babu, V. J., Vempati, S., \& Ramakrishna, S. (2013). Conducting polyaniline-electrical charge transportation. Materials Sciences and Applications, 4(01), 1. http://dx.doi.org/10.4236/msa.2013.41001

6-Bajpai, A., Bajpai, J., \& Soni, S. (2009). Designing polyaniline (PANI) and polyvinyl alcohol (PVA) based electrically conductive nanocomposites: Preparation, characterization and blood compatible study. Journal of Macromolecular Science $®$, Part A: Pure and Applied Chemistry, 46(8), 774-782. https://doi.org/10.1080/10601320903004533

7-Balkan, A., Armagan, E., \& Ince, G. O. (2017). Synthesis of coaxial nanotubes of polyaniline and poly (hydroxyethyl methacrylate) by oxidative/initiated chemical vapor deposition. Beilstein journal of nanotechnology, 8(1), 872-882. doi:10.3762/bjnano.8.89

8-Chang, Q., Zhao, K., Chen, X., Li, M., \& Liu, J. (2008). Preparation of gold/polyaniline/multiwall carbon nanotube nanocomposites and application in ammonia gas detection. Journal of materials science, 43(17), 5861-5866. https://doi.org/10.1007/s10853008-2827-3

9-Chen, S.-A., \& Hwang, G.-W. (1997). Structures and properties of the water-soluble self-acid-doped conducting polymer blends: sulfonic acid ringsubstituted polyaniline/poly (vinyl alcohol) and poly (aniline-co-N-propanesulfonic acid aniline)/poly (vinyl alcohol). polymer, 38(13), 3333-3346. https://doi.org/10.1016/S0032-3861(96)00880-4

10-Dogan, S., Akbulut, U., Yalcin, T., Suzer, S., \& Toppare, L. (1993). Conducting polymers of aniline II. A composite as a gas sensor. Synthetic Metals, 60(1), 27-30. https://doi.org/10.1016/0379$\underline{6779(93) 91179-6}$
11-Fratoddi, I., Venditti, I., Cametti, C., \& Russo, M. V. (2015). Chemiresistive polyaniline-based gas sensors: A mini review. Sensors and Actuators B: Chemical, 220, 534-548. https://doi.org/10.1016/j.snb.2015.05.107

12-Ge, T., Hu, X., Tang, K., \& Wang, D. (2019). The Preparation and Properties of Terephthalyl-AlcoholModified Phenolic Foam with High Heat Aging Resistance. Polymers, 11(8), 1267. https://doi.org/10.3390/polym11081267

13-Ghobashy, M. M., Alkhursani, S. A., \& Madani, M. (2018). Radiation-induced nucleation and $\mathrm{pH}$ controlled nanostructure shape of polyaniline dispersed in DMF. Polymer Bulletin, 75(12), 54775492. https://doi.org/10.1007/s00289-018-2336-8

14-Guerrero, G., Hägg, M.-B., Simon, C., Peters, T., Rival, N., \& Denonville, C. (2018). CO2 separation in nanocomposite membranes by the addition of amidine and lactamide functionalized POSS ${ }^{\circledR}$ nanoparticles into a PVA layer. Membranes, 8(2), 28. https://doi.org/10.3390/membranes8020028

15-Huang, J., \& Kaner, R. B. (2004). Nanofiber formation in the chemical polymerization of aniline: a mechanistic study. Angewandte Chemie International Edition, 43(43), 58175821.https://doi.org/10.1002/anie.200460616

16-Jabur, A. R. (2018). Effect of polyaniline on the electrical conductivity and activation energy of electrospun nylon films. International Journal of Hydrogen Energy, 43(1), 530-536. https://doi.org/10.1016/j.ijhydene.2017.04.005

17-Jianjun, H., Yuping, D., Jia, Z., Hui, J., Shunhua, L., \& Weiping, L. (2011). $\quad \gamma$-MnO2/polyaniline composites: Preparation, characterization, and applications in microwave absorption. Physica B: Condensed Matter, 406(10), 1950-1955. https://doi.org/10.1016/j.physb.2011.02.063

18-Jin, E., Lu, X., Bian, X., Kong, L., Zhang, W., \& Wang, C. (2010). Unique tetragonal starlike polyaniline microstructure and its application in electrochemical biosensing. J Mater Chem, 20(15), 3079-3083. DOI: $10.1039 / \mathrm{B} 925753 \mathrm{E}$

19-Khalid, M., Tumelero, M. A., Brandt, I., Zoldan, V. C., Acuña, J. J., \& Pasa, A. A. (2013). Electrical conductivity studies of polyaniline nanotubes doped with different sulfonic acids. Indian Journal of Materials Science, 2013. http://dx.doi.org/10.1155/2013/718304

20-Khan, M. D. A., Akhtar, A., \& Nabi, S. A. (2015). Investigation of the electrical conductivity and optical property of polyaniline-based nanocomposite and its application as an ethanol vapor sensor. New Journal of Chemistry, 39(5), 3728-3735. DOI: 10.1039/C4NJ02260B

21-Kim, M. J., Park, Y. I., Youm, K. H., \& Lee, K. H. (2004). Gas permeation through water-swollen 
polysaccharide/poly (vinyl alcohol) membranes. Journal of applied polymer science, 91(5), 32253232. https://doi.org/10.1002/app.13520

22-Lin, C., Hwang, B., \& Lee, C. (1999). Sensing behaviors of the electrochemically co-deposited polypyrrole-poly (vinyl alcohol) thin film exposed to ammonia gas. Materials Chemistry and physics, 58(2), 114-120. https://doi.org/10.1016/S02540584(98)00261-2

23-Lin, C., Liu, S., \& Hwang, B. (2001). Study of the actions of BTEX compounds on polypyrrole film as a gas sensor. Journal of applied polymer science, 82(4), 954-961. https://doi.org/10.1002/app.1928

24-MacDiarmid, A., \& Epstein, A. J. (1994). The concept of secondary doping as applied to polyaniline. Synthetic Metals, 65(2-3), 103-116. https://doi.org/10.1016/0379-6779(94)90171-6

25-MacDiarmid, A. G. (2001). "Synthetic metals": a novel role for organic polymers. Current Applied Physics, 1(4-5), 269-279. https://doi.org/10.1016/S1567-1739(01)00051-7

26-Malinauskas, A. (2001). Chemical deposition of conducting polymers. polymer, 42(9), 3957-3972. https://doi.org/10.1016/S0032-3861(00)00800-4

27-Matsuguchi, M., Io, J., Sugiyama, G., \& Sakai, Y. (2002). Effect of NH3 gas on the electrical conductivity of polyaniline blend films. Synthetic Metals, 128(1), 15-19. https://doi.org/10.1016/S03796779(01)00504-5

28-Mercante, L. A., Facure, M. H., Sanfelice, R. C., Migliorini, F. L., Mattoso, L. H., \& Correa, D. S. (2017). One-pot preparation of PEDOT: PSS-reduced graphene decorated with $\mathrm{Au}$ nanoparticles for enzymatic electrochemical sensing of $\mathrm{H} 2 \mathrm{O} 2$. Applied Surface Science, 407, 162-170. https://doi.org/10.1016/j.apsusc.2017.02.156

29-Miller, D. D., \& Chuang, S. S. (2016). The effect of electron-donating groups and hydrogen bonding on $\mathrm{H} 2 \mathrm{~S}$ capture over polyethylene glycol/amine sites. The Journal of Physical Chemistry C, 120(2), 11471162. https://doi.org/10.1021/acs.jpcc.5b11796

30-Mishra, A. K., \& Ramaprabhu, S. (2012). Nanostructured polyaniline decorated graphene sheets for reversible CO 2 capture. J Mater Chem, 22(9), 3708-3712. DOI: $10.1039 / \mathrm{C} 2 \mathrm{JM} 15385 \mathrm{H}$

31-Mohamoud, M. A. (2013). Polyaniline/poly (vinyl alcohol)(PAN/PVA) composite films: the synergy of film structural stiffening, redox amplification, and mobile species compositional dynamics. Journal of Solid State Electrochemistry, 17(11), 2771-2782. https://doi.org/10.1007/s10008-013-2174-4

32-Nicolas-Debarnot, D., \& Poncin-Epaillard, F. (2003). Polyaniline as a new sensitive layer for gas sensors. Analytica Chimica Acta, 475(1-2), 1-15. https://doi.org/10.1016/S0003-2670(02)01229-1
33-Osorio-Fuente, J. E., Gómez-Yáñez, C., HernándezPérez, M. d. 1. Á., \& Pérez-Moreno, F. (2014). Camphor sulfonic acid-hydrochloric acid codoped polyaniline/polyvinyl alcohol composite: Synthesis and characterization. Journal of the Mexican Chemical Society, 58(1), 52-58.

34-Qi, J., Xu, X., Liu, X., \& Lau, K. T. (2014). Fabrication of textile based conductometric polyaniline gas sensor. Sensors and Actuators B: Chemical, 202, 732-740. https://doi.org/10.1016/j.snb.2014.05.138

35-Quillard, S., Louarn, G., Lefrant, S., \& MacDiarmid, A. (1994). Vibrational analysis of polyaniline: a comparative study of leucoemeraldine, emeraldine, and pernigraniline bases. Physical Review B, 50(17), 12496.

DOI:https://doi.org/10.1103/PhysRevB.50.12496

36-Reddy-Noone, K., Jain, A., \& Verma, K. K. (2007). Liquid-phase microextraction and $\mathrm{GC}$ for the determination of primary, secondary and tertiary aromatic amines as their iodo-derivatives. Talanta, 73(4),

684-691.

https://doi.org/10.1016/j.talanta.2007.04.043

37-Sengupta, P. P., Barik, S., \& Adhikari, B. (2006). Polyaniline as a gas-sensor material. Materials and manufacturing processes, 21(3), 263-270. https://doi.org/10.1080/10426910500464602

38-Srivastava, S., Sharma, S., Agrawal, S., Kumar, S., Singh, M., \& Vijay, Y. (2010). Study of chemiresistor type CNT doped polyaniline gas sensor. Synthetic Metals, 160(5-6), 529-534. https://doi.org/10.1016/j.synthmet.2009.11.022

39-Stejskal, J., Sapurina, I., \& Trchová, M. (2010). Polyaniline nanostructures and the role of aniline oligomers in their formation. Progress in Polymer Science, 35(12), 1420-1481. https://doi.org/10.1016/j.progpolymsci.2010.07.006

40-Stockton, W., \& Rubner, M. (1997). Molecular-level processing of conjugated polymers. 4. Layer-by-layer manipulation of polyaniline via hydrogen-bonding interactions. Macromolecules, 30(9), 2717-2725. https://doi.org/10.1021/ma9700486

41-Sustkova, H., Posta, A., \& Voves, J. (2019). Polyaniline emeraldine salt as an ammonia gas sensor-Comparison of quantum-based simulation with experiment. Physica E: Low-dimensional Systems and Nanostructures, 114, 113621. https://doi.org/10.1016/j.physe.2019.113621

42-Tiggemann, L., Ballen, S., Bocalon, C., Graboski, A. M., Manzoli, A., de Paula Herrmann, P. S., . . . Steffens, C. (2016). Low-cost gas sensors with polyaniline film for aroma detection. Journal of Food Engineering, 180, $16-21$. https://doi.org/10.1016/j.jfoodeng.2016.02.006

43-Wan, M., Srivastava, A. K., Dhawan, P. K., Yadav, R. R., Sant, S. B., Kripal, R., \& Lee, J.-H. (2015). High dielectric response of 2D-polyaniline nanoflake 
based epoxy nanocomposites. RSC Advances, 5(60), 48421-48425. DOI: $\underline{10.1039 / \mathrm{C} 5 \mathrm{RA} 05660 \mathrm{H}}$

44-Wang, X.-Q., Xin, B.-J., \& Xu, J. (2013). Preparation of conductive PANI/PVA composites via an emulsion route. International Journal of Polymer Science, 2013.

http://dx.doi.org/10.1155/2013/903806
45-Wang, Y., \& Rubner, M. (1992). An investigation of the conductivity stability of acid-doped polyanilines. Synthetic Metals, 47(3), 255-266. https://doi.org/10.1016/0379-6779(92)90366-Q 